\title{
CRITERIA FOR THE SELECTION OF TOURISM DESTINATIONS BY STUDENTS FROM DIFFERENT COUNTRIES
}

\author{
Maciej DĘBSKI", Wojciech NASIEROWSKI** \\ *University of Social Sciences, Warsaw, Poland \\ e-mail: m.debski@san.edu.pl \\ **University of Social Sciences Warszawa, Poland, and \\ University of New Brunswick, PO Box 4400, Fredericton, Canada \\ e-mail: nasierow@unb.ca
}

\begin{abstract}
The objective of this paper is to identify selected aspects of the management of information about prospective tourist destinations by young people (students) from Canada, Poland, and Trinidad and Tobago. On the basis of a questionnaire study, the ranking of preferences of respondents (i.e., the main criteria of destination choice) has been presented. Students were selected as respondents - as a "convenient sample" - in this privately funded study. A variety of aspects related to comfort (and convenience) and attractiveness have been identified as most important to the choice of destination. These are also leading motives that may form a platform for advertising campaigns and suggestions for regional development. This examination has been done mainly with the use of analysis of averages, Spearman correlation coefficients, and various approaches to factor analysis. It turns out that despite very different characteristics of respondents from the three countries, both their preferences and motives for promotion of the destination are very similar. Conclusions can be helpful for travel agencies and those responsible for the development of tourism infrastructure, as well as for the organization of further studies on the subject. The combination of various statistical tools used when examining the subject and the finding - that is, the similarity of preferences between travelers - can be regarded as new value when examining the subject.
\end{abstract}

Keywords: tourism, marketing communications, young tourists, destination attractiveness.

\section{1}

Introduction

There are several items that have an impact on the selection of a travel destination. These items include examination of the destination from perspectives such as culture, economic and political situations, climate, and accessibility of attractions (e.g., cultural events, monuments, and festivals), as well as from the viewpoint of the customers, their age and sex, family and socioeconomic status, the size of the domicile location, their financial and physical wellbeing, etc. (e.g., Vukicz et.al., 2015; Kim et.al., 2007; Dwyer, Kim, 2010; Blumenberg et.al., 2012).

These characteristics are often interrelated, thus creating an even broader platform of preferences, and associated constraints. The identification of particular attractions related to the promotion of the destination and interrelations between these items are important to the identification of efficient marketing efforts focused on a particular group of customers.
Taking into account these items in order to satisfy the needs and wants of prospective clients is complex. This complexity hampers the actions of local authorities in the administration of initiatives for regional development as well as for tourist agencies attempting to design and focus advertising campaigns.

Tourism is an important element of the contemporary economy. Income from this economic sector accounts for some $\$ 1,245$ million. In 2014, tourism generated $9 \%$ of the World GDP and accounted for some $10 \%$ of employment (UNWTO, 2015, p.2). As presented by Śniadek, the average age of the world population is currently 26 years, yet by 2050 , it is estimated to be 36 years (Śniadek, 2006, in: Graja-Zwolińska, Spychała, 2012, p.54). Still the largest group of tourists comprised of seniors.

However, one can also observe an increase in the expenditures by young people for tourism purposes (Demeter, Bratucu, 2014, p.115). As young people 
are becoming a more and more attractive group for tourism agencies, and for those responsible for regional development, some study is warranted to explore how one may effectively recognize their preferences, wants, needs, and constraints in order to draw their attention towards the destination or to experience tourism firms' offerings.

The need to examine these statistics comes from the logistics associated with efficient marketing communications. Consequently, two aspects should be addressed:

1) The recognition of factors that are most relevant to acquisition of the offer by the young tourists. This is the main objective addressed in this paper.

2) The recognition of sources of information used by customers before making the decision relative to the consumption of the tourism offer. In the case of young people, the Internet is most likely the main source of information about the destination (Nasierowski, Dębski, 2015).

As a consequence of the above comments, the following hypotheses are examined:

- Hypothesis 1 (H1): There are different elements that impact the selection of the destination for different groups of prospective tourists; and

- Hypothesis 2 (H2): There are no means to isolate these elements from the criteria used for the selection of destination that are uniform for all distinctive groups of tourists, regardless of characteristics of these groups.

The importance of verification of such hypotheses originates from aspects relative to the selection of the destination. Evidence to support or reject such hypotheses may help determine the key elements that impact the destination choice subject to characteristics of prospective tourists. These aspects are addressed in literature from many perspectives.

One perspective concerns the general aspects of tourism (e.g., Kozak, Rimmington, 1999; Sirakaya et al., 1996; Crompton, 1992; Wong, Kwong, 2003; Bizirgianni, Dionysopoulou, 2013; Fyhri et al., 2011) and the motives for different forms of tourism (e.g., Doran et al., 2014). The other perspective concerns perceptions of attractiveness and the competitive position of the destination (e.g., Buhalis 2000; Chen, Tsai, 2007; Decorp, Snelders, 2003; Chen, Gursoy,
2001; Panter et al., 2008; Kozak, Rimmington, 1999; King et al,. 2015). The third perspective, on which we direct our interest, relates to the choice criteria of destination by customers (Park, Jei, 2010; Yousefi, Marzuki, 2012; Cho, 2009; Bond, Falk, 2013; and in particular Eugenio-Martin, 2003). Within this area, we have chosen to confine our focus to young people (e.g., Moisa, 2010; Kim, Jogaratnam, 2003; Sung, Hsu, 2010; Lam, Hsu, 2005).

A questionnaire study conducted in Canada, Poland, and Trinidad and Tobago (T\&T) examined destination preferences. In order to address these preferences, the following structure for the presentation has been selected. In Section 2, selected preferences pertaining to efficient marketing communication have been described. Section 3 explores ranking of preferences when choosing a destination.

The factor analysis of prospective preferences in the selection of a destination has been used in order to identify the main motives that drive the choice of prospective young tourists, which may also inform the direction of advertising choices. The results of such an analysis have been presented in Section 4. Conclusions pertaining to the particulars of tourism and suggestions for further study have been presented in Section 5.

\section{Marketing Communication Management Relative to the Area of the Selection of Destination}

The reports of the World Tourism Organization (WTO) contain data that suggest that the presence of young people as customers in the tourism sector has increased. The number of trips has increased from 136 to 187 million between 2000 and 2010 and account for some one-fifth of all world travelers. Expenditures for such trips amounted to US \$165 million in 2010 (The Power ..., 2011, pp.6-8). It has also been noted that generation $\mathrm{Y}$ can be characterized by higher tourism activity than their predecessors (Vukic et al., 2015, pp.482-491).

The increase in expenditures toward tourism by young people is determined mainly by two factors: being interested in the world, and education (Youth Travel..., 2008, p. xi). The definition of "youth travel" adopted by WTO also follows such a pattern: 
"youth travel includes all independent trips for periods of less than one year by people aged 16-29 which are motivated, in part or in full, by a desire to experience other cultures, build life experience and/or benefit from formal and informal learning opportunities outside one's usual environment" (Dionysopoulou, Mylokanis, 2013, p.23). The place of residence may indirectly indicate that it is an important aspect for young travelers and is related to:

- The wealth level of the society, which determines the possibility to finance trips by young people in order to satisfy their objectives, or earning some profits for less wealthy parts of the society,

- Availability of attractive locations in other cultures and countries; yet these items may be very different for North America tourists than for tourists from Europe due to shorter distances to reach appealing locations, and

- Patterns pertaining to travel in a given society for example, in the North America, there will be longer trips, whereas in Europe, trips are generally shorter in time or distance traveled is shorter.

There are also other distinct characteristics and patterns of travel by young people. Young people have more "free time," so trips are often long and more expensive. There appears to be evidence that young people choose to take time off their studies or from work in order to travel (Yoon, 2014, p.1014).

An additional motive for youth travel is a desire to learn more about foreign locations. Tourists do not, however, often return to places visited previously. For young travelers, the probability that they return is higher owing to the fact that they have more years of life to do so. On the other hand, young people are prone to seek novelties and are frequently pioneers in identifying attractive destinations. They are less discouraged because of social unrest, diseases, natural disasters, or terrorist threats (Vukicz et al., 2015, p.82) that may have a negative impact on such destinations (e.g., France, Belgium, Egypt, or Turkey at the beginning of 2010s).

Kim et al. (2007, in: Tibon 2012, p.1393) have identified typical motives for traveling presented by young people. These include knowledge, sports, adventure, relaxation, lifestyle, bragging about their travels, and family. Some of these elements can be regarded as universal and may be typical for other age groups, though some are specific to young people - gaining knowledge, for example.

When examining characteristics that are responsible for the demand related to a chosen destination, Niezgoda (2012) has indicated several reasons that may be pivotal for the selection of the destination: economic, legal, geographical, and sociopsychological conditions, and the role of mass media. When examining these preferences, one should keep in mind that a selected city or region is typically very specific and somewhat unique. They are characterized by many elements that impact their competitive position as travel destinations. As pointed out by Panasiuk (2015, p.431), beyond traditionally recognized tourism agencies, there are institutions, as well as local authorities, responsible for the creation of the tourism offer, for making it available, that may impact the creation of a climate friendly for tourists.

Dwyer and Kim (2010, pp. 400-405) specified some 120 items associated with the competitiveness of a destination and grouped them into categories such as endowed resources, created resources, supporting factors, destination management, situational conditions, and market performance indicators. Enright and Newton (2005) have specified two factors of a competitive destination, and only one indirectly relates to tourism: "labor cost and skills, the level of retail sector development, the level of technological advancement, strategies of local companies, political stability, anti-corruption policy, the level of educational system, strong currency and steady prices" (in Navickas, Malakauskaite, 2009, p.39). These elements are important to the marketing of a destination that is independent of people and agencies responsible for the creation of tourism policy and the tourism experience.

Factors of competitiveness of the tourism destination were addressed by many researchers (e.g., Vanhove, 2002; Dwyer, Kim, 2003; Mechinda et al., 2010). It was emphasized that the proper management of the destination site is important and includes marketing and promotion (Grzinic, Saftic, 2012, pp.63-64). These elements correspond to the customers' preferences. There were also attempts to link elements of competitiveness with the demand for the specific products. 
For example, Kaushik et al. (2010) examined tourism-related habits of the Hindu people and assumed the existence of relationships between variables such as age, sex, background of the tourists, occupation, income, and their impact on the selection of the destination. The key elements related to the choice of the destinations are "communication, objectivity, basic facilities, attraction, support services, distinctive local features and psychological and physical environment" (Kaushnik et al., 2010, p.128).

On the basis of the examination of the above factors and previously mentioned extensive reports about various approaches delineating attractiveness of the destination and young tourists' needs, wants, and preferences, the questionnaire for our study was prepared. In this study, we have concentrated on the response to the question, What aspects/elements are examined by respondents - young people, students when selecting the destination for their trips? The answer to this question rests with the motives for marketing/promotional campaigns concentrated on young people.

\section{$3 \quad$ Data and its Statistical Analysis}

The questionnaire was distributed to students in three countries that vary greatly in their characteristics: Canada (Fredericton), Poland (Warsaw), and T\&T (Port of Spain). It was a "convenient sample" for the authors. In this preliminary self-financed study, the sample is not representative. There were no control questions, so the consistency of responses was verified by comparisons between the responses to various parts of the questionnaire. The disadvantage of the sample is also related to the fact that investigated samples are different in terms of response numbers, age of respondents, and residence characteristics of respondents (e.g., different size). Groups of respondents may differ in terms of wealth, culture, and attractions available in places of residence.

Thus, despite valuable information collected, this study and its findings should be regarded as preliminary in testing our methodology for further investigation of the subject. Respondents were asked 17 questions, with answers in the scale 1-5: 1 being not important, 5 being very important elements in the selection of a destination for traveling (to the selected city or region).

About 235 responses were collected in Poland, and 201 are being further analyzed. Of these, 70\% of the respondents were aged younger than 25 years; $56 \%$ were residents of Warsaw, and the remaining portion residents of neighboring cities. Warsaw can be regarded as a very attractive tourist destination, with a host of cultural events and sites. It is a city with many administrative facilities, where several headquarters of big companies (as well as multinational companies) are located, along with many universities. These particulars are important, because young travelers may seek unique attractions when traveling - compared to those available at home. For them, traveling to destinations with different cultural characteristics and attractions is relatively simple because of the short distance necessary to travel from their city of residence. Travel may often be considered a symbol of status for this group.

Canadian respondents $(n=110)$ are predominantly residents of Fredericton (New Brunswick), a city with some 50,000 inhabitants. It is a pleasant and small city in a quiet, relatively rich environment, with a few historic attractions, a growing art and music scene, a major art gallery, and opportunities for summer and winter sports. Major employers include the Canadian government, two universities, a hospital, and the police, where salaries are generally above average. There are no big companies and essentially no industrial sector, though there is a developing knowledge sector, with most employment sourced from the government and service sector as a result of being the provincial capital. Travel abroad is less common here, with the exception of university and government populations, which make up a large percentage of the city's population.

Respondents in T\&T $(n=121)$ reside mainly in Port of Spain. This is ethnically, culturally, and, from the viewpoint of religion, a very diverse society. Some $50 \%$ of respondents are young people, $50 \%$ are 30 to $>35$ years old, studying part-time, employed, and with families. Several respondents have relatives or friends living in California, Florida, and, at times, Toronto or Montreal, and their traveling can been associated with visiting these friends and family (authors' assumption). 
To be noted: average income per capita in the sampled three countries are as follows: Canada, $\$ 43,248$; Poland, \$12,494; T\&T, \$20,444 (http://data.world bank.org/indicator/NY.GDP.PCAP.CD, accessed: 30 September 2016).
Evaluation of elements important to the selection of destination is presented in Table 1.

Table 1. Elements important in the selection of a destination by respondents from Poland, Canada, and T\&T

\begin{tabular}{|l|c|c|c|}
\hline & \multicolumn{3}{|c|}{ ELEMENT $\rightarrow$ average for } \\
\hline & Poland & T\&T & Canada \\
\hline Journey costs & 4.42 & 4.39 & 4.22 \\
\hline Climate & 4.37 & 3.88 & 3.84 \\
\hline Easy Access to attractions & 4.30 & 4,15 & 3,53 \\
\hline $\begin{array}{l}\text { Variety of leisure and recreation offered } \\
\text { (swimming pools, Cinema, parks, playgrounds) }\end{array}$ & 4.16 & 4.40 & 3.66 \\
\hline Quality of accommodation and facilities & 4.13 & 4.39 & 3.99 \\
\hline Quality of catering/restaurants facilities & 4.06 & 4.18 & 3.62 \\
\hline Easy Access & 3.98 & 3.80 & 3.17 \\
\hline Flora, fauna and natural environment & 3.91 & 3.15 & 3.00 \\
\hline Quality and accessibility of shops & 3.68 & 4.04 & 3.19 \\
\hline Clubs, theme parks, entertainment & 3.48 & 3.88 & 3.32 \\
\hline Quality and efficiency of local transport & 3.46 & 4.17 & 3.15 \\
\hline Special events, festivals & 3.23 & 3.53 & 3.47 \\
\hline Architectural attractions. museums & 2.96 & 3.04 & 2.96 \\
\hline $\begin{array}{l}\text { Opportunity for practicing a specific sport and related } \\
\text { facilities }\end{array}$ & 2.93 & 2.42 & 2.13 \\
\hline Destination Brand (known, popular) & 2.77 & 3.23 & 3.03 \\
\hline Folk art of a specific area & 2.38 & 2.56 & 2.14 \\
\hline Presence of places of religious worship & 2.04 & 2.46 & 1.64 \\
\hline \hline & 3.54 & 3.63 & 3.18 \\
\hline \multicolumn{1}{|c|}{ Number of responses } & 225 & 121 & 110 \\
\hline
\end{tabular}

Responses from the three countries were checked for similarity of preferences using Spearman correlation coefficient. The results indicate the following: Poland vs T\&T $=0.790$; Poland vs Canada $=0.880$; $\mathrm{T} \& \mathrm{~T}$ vs Canada $=0.876$; with the significance level of 0.000 . Thus, despite many differences among respondents - their age, wealth, etc. - criteria used for the selection of destination can be regarded as similar.

The most important factor for respondents when selecting a destination is the cost of the journey, followed by climate, easy access to attractions, and the variety of leisure and recreation offered. Similar results were obtained by Buchta and Skiert (2012, p.26) when examining students' preferences: cost of the journey, sight-seeing, and climate received the highest scores. Young people who are active and would like to travel, and concurrently are younger than 25 years of age, do not have enough money in order to achieve all the objectives associated with traveling, especially when they use their own resources. This constitutes an important constraint for youth travel, especially when they have no other financial support. 
As suggested by Panasiuk (2014, p.129) tourism satisfies higher level needs and calls for a consumption of funds. An important, but not critical, criterion, as presented in Table 2, concerns comfort associated with traveling: quality of accommodation (hotels) and facilities, quality of catering and restaurant facilities, quality and accessibility of retail shops, and the variety of leisure and recreation offered. It seems somewhat strange that climate is the second most important element when selecting destination, because it does not intuitively correspond to the logic of the decision-making processes of young tourists. For respondents from T\&T, climate is not important. On the other hand, one can accept that it is a universal element important to all tourists - regardless of their age. In conclusion, when preparing a tourism offer for young tourists, it is crucial to emphasize the possibility of active recreation, with a variety of choices of an acceptable quality, while being mindful of costs.

As a rule, young people are not overly interested in: the presence of places for religious worship, folk art, destination brand (known, popular), architectural attractions (museums) or, more surprisingly, various leisure recreations (such as swimming pools, cinema, parks, and play grounds).

The ranking of travel preferences by different groups of respondents, who are highly and positively correlated at the acceptable significance level, is somewhat surprising. Despite fundamental differences in the demographics of respondents - with only two similar elements: age, and that they are students the rankings of contributing factors important to the choice of destination are similar.

\section{Examination of Responses Based on Factor Analysis}

Examination of average values of various factors that impact the selection of the destination provides an overview of typical preferences. These items may assist in the selection of specific marketing strategies presented to various groups of customers. On the basis of the results of factor analysis, an attempt has been made to isolate motives for going to a specified destination/city/region. We expected that factor analysis results might provide different outcomes for respondents from Canada, Poland, and T\&T. It turned out that for the analysis of the countries, one can identify a different number of variables that denote preferred destinations for traveling. Only in the case of Poland, all the variables can be used. In the case of Canada, we have to exclude four variables:

- opportunity for practicing a specific sport and related facilities,

- architectural attractions, museums,

- presence of places of religious worship, and

- flora, fauna, and natural environment.

In the case of $T \& T$, we have to exclude three elements:

- opportunity for practicing a specific sport and related facilities,

- presence of places of religious worship, and

- climate.

The main reason for excluding these elements was their lower than 0.5 values in the anti-imagecorrelation matrixes and the Kaiser-Meyer-Olkin (KMO) Measure of Sampling Adequacy index.

The next steps in the analysis indicated that one can identify key motives for the selection of the destination - a city or region. The justification rests with acceptable values of:

- the Determinant of Correlation Matrix (DCM) the lower the better, and

- substantially higher than 0.5 value of KMO.

The discussed dimensions for the countries under investigation are as follows:

- Canada: $\mathrm{DCM}=0.35 ; \mathrm{KMO}=0.733$,

- Poland: $\mathrm{DCM}=0.019 ; \mathrm{KMO}=0.742$, and

- $\mathrm{T} \& \mathrm{~T}: \mathrm{DCM}=0.012 ; \mathrm{KMO}=0.802$.

The method of main elements in the factor analysis was used in order to determine the motives for the selection of the destination. Both conditions, here the low value of DCM and high value of KMO, are satisfied. The optimum number of factors was determined based on the examination of the scatter plots. In order to use a simple interpretation of factors, the Oblimin rotation was used. 
The analysis of results of factor analysis suggests the existence of two factors for all three examined groups of respondents. These are comfort (which includes convenience) and attractiveness. The interpretation of these constructs may be as follows: Comfort: "something that brings aid, support, or satisfaction. An appurtenance or condition furnishing mental or physical ease" (Websters ..., 1986, p.454). Convenience: "A favourable or advantageous condition, state, or circumstance. Something suited to ones material wants, freedom from difficulty, discomfort, or trouble" (Websters ..., 1986, p.497). Attractiveness: "able to cause to approach by influencing the will or appealing to the senses. Having qualities that arouse interest, pleasure, or affection in the observer" (Websters ..., 1986, p.141).

In our research, comfort and attractiveness may relate to different aspects for the different groups of respondents. Certainly, an issue of interpretation of these factors - comfort, convenience, attractiveness - is open for discussion, as they are very broad, and their interpretation depends on many elements: culture, family status, age, wealth, education, preferences, etc.

Table 2. The selection of elements that create the scale of comfort (and convenience) and attractiveness for three groups of respondents

\begin{tabular}{|c|c|c|c|}
\hline & Poland & Canada & $\mathrm{T} \& \mathrm{~T}$ \\
\hline \multicolumn{4}{|c|}{ COMFORT (and CONVENIENCE) } \\
\hline Quality of accommodation and facilities & 0.538 & 0.679 & 0.733 \\
\hline Journey costs & 0.597 & & 0.655 \\
\hline Quality and accessibility of shops & 0.680 & 0.579 & 0.719 \\
\hline $\begin{array}{l}\text { Variety of leisure and recreation offered (swimming } \\
\text { pools, cinemas, parks, playgrounds) }\end{array}$ & 0.614 & 0.664 & 0.551 \\
\hline Climate & & 0.700 & \\
\hline Quality and efficiency of local transport & 0.666 & 0.622 & 0.710 \\
\hline Easy access & 0529 & & 0.605 \\
\hline Quality of catering/restaurants facilities & 0.676 & 0.778 & 0.572 \\
\hline Clubs, theme parks, entertainment & & 0.510 & \\
\hline Easy access to attractions & 0.575 & & 0.815 \\
\hline Destination brand (known, popular) & & 0.738 & 0.517 \\
\hline \multicolumn{4}{|c|}{ ATTRACTIVENESS } \\
\hline Easy access & & 0.741 & \\
\hline Easy access to attractions & & 0.677 & \\
\hline Architectural attractions, museums & 0.623 & & 0.759 \\
\hline Special events, festivals & & 0.585 & 0.656 \\
\hline Flora, fauna and natural environment & 0.585 & & 0.688 \\
\hline Folk art of a specific area & 0.652 & & 0.738 \\
\hline
\end{tabular}


Items describing these factors may overlap, e.g. what is comfortable might also be interpreted as attractive, and there may exist substantial differences in the interpretation of these factors in different countries.

Table 2 presents items that form the scale of comfort (and convenience) and attractiveness along with their factor loadings (Pearson correlation coefficients that denote the strength of relations among variables) for the three countries.

The models arrived at based on the results of factor analysis explain:

- $40.7 \%$ of variance for Canada,

- $34.7 \%$ of variance for Poland, and

- $44.5 \%$ of variance for $\mathrm{T} \& \mathrm{~T}$.

Unidentified elements are responsible for the remaining portion of the variance. These are relatively low values, and these results may be the consequence of the formulation of questions in the questionnaire that is, if they were not focused enough or if they might have been interpreted differently. Also, there exists the potential for different interpretations of the wording used in the questionnaire by the different groups of respondents.

It is also interesting that climate is one of the critical criterion of destination choice (based on the examination of average values, as presented in Table 1), yet climate gets a low value when factor analysis results are examined.

Next, brand recognition, folk art, and the presence of places for religious worship are not important items for the selection of the destination, neither when using results or average values, nor when using the results of the factor analysis. Therefore, these elements should not be used as the leading motives in marketing campaigns promoting the destination for young people. Surprisingly, the variety of leisure and recreation offered are not among the important items for young people.

When searching for the more universal method to identify "what is important for young people when they choose a tourist destination," the factor analysis was used for all respondents in our study. The initial analysis has provided evidence that all variables (questions in the questionnaire) can be used in the factor analysis. The following contributes to such a conclusion: $\mathrm{DCM}=0.280 ; \mathrm{KMO}=0.808$; Measure Sampling Adequacy $>0.50$ for all variables.

The further analysis of data can be carried out using two approaches:

- VARIANT 1 - Using two factors as the optimal solution, and

- VARIANT 2 - Using eigenvalue $>1$ as the selection criterion.

\section{VARIANT 1}

Similar to factor analysis for the countries in the sample, two factors were accepted as the optimal solution. The Oblimin rotation with the Kaiser normalization was used to identify factors and their elements. Table 3 shows the composition of these elements and respective factor loadings for the variables that indicate the strength of relationships between variables.

The first category (comfort and convenience) concerns the infrastructure of the location, how easy it is to travel there, and the costs associated with the journey.

The second relates to the specific physical features of the destination (attractiveness). Such a model explains $34.8 \%$ of the variance of the investigated phenomena - here, the motives for the selection of the said destination. The rest of the variance can be explained by unidentified elements.

The results show that factor analysis results - with respect to comfort, convenience, and attractiveness, with some minor exceptions in the case of Canada are similar. Irrespective of differences in the characteristics of the three groups of respondents, the elements that make factors are similar - and the motives for the selection of the destination are similar.

In the case of respondents from two countries, the option to practice various sport disciplines and the related infrastructure, along with places of religious worship, are not examined: these elements do not fit the model we developed (with lower than 0.5 value of the factor loadings). 
Table 3. Structure matrix for two factors analysis for the three countries

\begin{tabular}{|l|c|c|}
\hline & ELEMENTS & ATTRACTIVENESS \\
\hline Quality of catering/restaurants facilities & 0.694 & 0.320 \\
\hline Easy access to attractions & 0.692 & 0.265 \\
\hline Quality and accessibility of shops & 0.673 & 0.145 \\
\hline $\begin{array}{l}\text { Variety of leisure and recreation offered } \\
\text { (swimming pools, cinemas, parks, playgrounds) }\end{array}$ & 0.654 & 0.099 \\
\hline Quality and efficiency of local transport & 0.642 & 0.252 \\
\hline Quality of accommodation and facilities & 0.627 & 0.088 \\
\hline Journey costs & 0.546 & 0.051 \\
\hline Easy access & 0.541 & 0.175 \\
\hline Clubs, theme parks, entertainment & 0.477 & 0.209 \\
\hline Destination brand (known, popular) & 0.468 & 0.157 \\
\hline Climate & 0.443 & 0.062 \\
\hline \hline Folk art of a specific area & 0.177 & 0.749 \\
\hline Architectural attractions, museums & 0.027 & 0.633 \\
\hline Flora, fauna, and natural environment & 0.230 & 0.591 \\
\hline Presence of place of religious worship & 0.158 & 0.583 \\
\hline Special events, festivals & 0.279 & 0.417 \\
\hline $\begin{array}{l}\text { Opportunity for practicing a specific sport and related } \\
\text { facilities }\end{array}$ & 0.085 & 0.309 \\
\hline
\end{tabular}

For Polish respondents, "destination brand (known, popular)" is not an element of "comfort." For Canadian respondents, "ease of access" and "quality and efficiency of local transportation" (these elements may be linked one to another) are not items related to comfort, but to attractiveness. This may result from the fact that communication infrastructure in Canada is well-developed, and with the lack of experience, respondents might have assumed that the similar infrastructure exists in other destinations.

Such results allow us to conclude for hypothesis $\mathrm{H} 2$ : In the selection of destination, it is impossible to isolate those elements that are universal, despite the characteristics of respondents; H2 cannot be confirmed. There are similar needs, preferences, and desires relative to the choice of the destination -regardless of cultural differences - which include characteristics of place of residence (size, economic situation, available attractions, etc.), age, sex, education levels, social status, and material and health conditions.

It can be concluded for hypothesis H1: There are different elements that impact the selection of the destination for different groups of prospective clients; H1 has not been confirmed. Despite the differences among the respondents, similar items are decisive in the selection of the destination. Such a result can be regarded as questionable, yet it appears to be what the numbers show.

\section{VARIANT 2}

Eigenvalue $>1$ can be used as the criterion for isolation of factors. The Oblimin rotation has been used. Consequently, five factors, which can be grouped as comfort and attractiveness, can be identified. 
Table 4. Structure matrix for Variant 2

\begin{tabular}{|l|c|c|c|c|c|}
\hline & \multicolumn{4}{|c|}{ FACTORS AND THEIR ELEMENTS } \\
\hline & 1 & 2 & 3 & 4 & 5 \\
\hline Quality and efficiency of local transport & 0.753 & 0.235 & 0.284 & 0.097 & 0.010 \\
\hline Easy access & 0.699 & 0.077 & 0.091 & 0.222 & 0.137 \\
\hline Quality and accessibility of shops & 0.699 & 0.075 & 0.364 & 0.211 & 0.044 \\
\hline Journey costs & 0.634 & 0.007 & 0.260 & -0.033 & 0.109 \\
\hline $\begin{array}{l}\text { Variety of leisure and recreation offered } \\
\text { (swimming pools, cinemas, parks, playgrounds) }\end{array}$ & 0.558 & -0.037 & 0.455 & 0.279 & 0.175 \\
\hline Folk art of a specific area & 0.086 & 0.764 & 0.212 & 0.077 & 0.178 \\
\hline Architectural attractions, museums & -0.024 & 0.667 & 0.046 & 0.204 & 0.006 \\
\hline Presence of places of religious worship & 0.297 & 0.645 & -0.048 & 0.026 & 0.010 \\
\hline \hline Quality of accommodation and facilities & 0.363 & 0.048 & 0.723 & 0.134 & -0.003 \\
\hline Quality of catering/restaurants facilities & 0.469 & 0.256 & 0.713 & 0.086 & 0.184 \\
\hline Destination brand (known. popular) & 0.162 & 0.123 & 0.619 & 0.373 & -0.140 \\
\hline Easy access to attractions & 0.552 & 0.134 & 0.563 & 0.143 & 0.313 \\
\hline Climate & 0.199 & -0.096 & 0.559 & -0.133 & 0.531 \\
\hline \hline Special events, festivals & 0.190 & 0.255 & 0.057 & 0.814 & 0.045 \\
\hline Clubs, theme parks, entertainment & 0.260 & -0.003 & 0.367 & 0.659 & 0.197 \\
\hline $\begin{array}{l}\text { Opportunity for practicing a specific sport and related } \\
\text { facilities }\end{array}$ & 0.043 & 0.038 & -0.081 & 0.251 & 0.721 \\
\hline Flora, fauna, and natural environment & 0.182 & 0.463 & 0.157 & -0.082 & 0.631 \\
\hline
\end{tabular}

Table 4 provides the composition of these categories and their factor loadings that show the strength of relations between indicators. The first and third factor deal with the infrastructure of the selected destination, ease of access and the infrastructure of the location, and ease of access and the associated costs (thus, comfort and convenience). The second factor addresses specific features of the destination (thus, attractiveness). The fourth one deals with entertainment (attractiveness element), and the fifth includes the possibility to engage in various sport activities and with the natural attractions of the location (attractiveness element).

Such a model of factor analysis explains $55 \%$ of the variance of the investigated phenomenon and also the motives behind the selection of the destination. The remaining part is explained by unidentified elements.

\section{Discussion of Results and Suggestions for Future}

The results of the study allow us to answer the research questions, What are the factors that are of prime importance to young tourists, and what is the key to communicating with them efficiently?

The critical elements related to the selection of the destination of travel by the respondents in our study, young people and students planning a trip, have been presented in Table 3. 
The most frequently mentioned items are the cost of traveling and the overall variety and the quality of the product. Thus, an examination of their preferences may be adequate promotion - keeping in mind their preferences, needs, wants, constraints - and not what travel agency leaders may believe is correct and will be the deciding factor in their choice. It is also important to identify an efficient means to communicate with clients - while not the main idea of this paper, this was explained earlier (Nasierowski, Dębski, 2015). Internet and social media networks are the main source of information for the young person wanting to travel. They use professional brochures or published advertisements to a much lesser extent, and they are more comfortable and experienced with the ease of access provided by the World Wide Web than older clients.

Several methods have been used when analyzing collected empirical material. Results indicate a high degree of similarity. These results show that comfort (and convenience) and attractiveness of the destination are most important. For a substantial portion of students, the key reason for traveling is to "relax" (Kim et al. 2006) or for "relaxation" (Ryan, Hang, 2006). There are also items associated with convenience when traveling - "seeing and learning," "fun and entertainment," or "adventure and thrill" (Kim et al., 2006) - that in turn are related to an interest in leisure, or, attractiveness. Consequently, when managing a tourism offer, special attention must be paid to comfort and attractiveness, though our results do not allow the isolation of the pivotal elements of comfort and attractiveness that are decisive to success.

While the existence of these two elements seems to be clear, there exists a high collinearity in expectations of respondents who are coming from very different countries. One might expect that comfort would be more important to respondents from Canada than those from Poland or T\&T. Our results do not confirm such an expectation.

Remember, attractiveness is a factor that should determine tourists' choice of a specific destination, as it contributes to a satisfaction from being there. However, it seems that comfort (and convenience) has a stronger impact on satisfaction. This observation has serious implications. Attractiveness should be emphasized in marketing communication for sales purposes, whereas comfort should be promoted in order to build the loyalty of clients - so that they return to the same destination and/or to the same travel agency. Such a line of reasoning is further justified when "seeing and learning" constitutes a strong motivation in selecting a destination. Tourists who have already seen natural or cultural attractions in a given destination may lose interest in returning, which, in this study, results in a decreased importance of the attractiveness factor.

These presented results should be regarded as preliminary - a test study with the use of an early, somewhat flawed, questionnaire. In spite of this, results show that further study in this area is warranted. There is an information gap between young tourists and travel agencies as they currently operate. The issue - whether such conclusions may be important for those responsible for regional development - is a topic for another investigation. There are, however, several very strong indications suggesting further studies are needed:

- A more comprehensive questionnaire (with more detailed questions) is recommended, yet the longer the questionnaire, the lower the response rate and the lower the reliability of responses. Plus, the control questions will further reduce the number of useful responses.

- We observe that a structured interview with representatives from travel agencies may be useful, at least with respect to the verification of their opinions about the possible requirements of prospective customers. It may be worthwhile to check the key criteria used by line-level travel agents when addressing the client: are there any specific regulations or procedures that must first be addressed, or are they simply consulting the brochure themselves? Managerial oversight might also be considered. It would be optional if travel agents were trained and certified before they are qualified to work in an agency. They should have opportunities for exploratory trips to explore travel offerings, and they should have to update their credentials regularly.

- In any further study on the subject, there is the perceived need to expand the section related to the characteristic features of the respondent: 
for example, family status (single with family, with children, etc.), sources of income, or sources of funding the trips.

- It may prove interesting if future research approaches take into account the differences between the preferred times of year young people can and wish to travel. This element may have an important impact on the responses to any questionnaire.

The results we obtained are a little surprising. One would expect cost to be one of the critical elements, and this has been confirmed. However, comfort is among the key elements of preferred travel destinations, which was unexpected of young people. One can also note the variety of sources of information and methods used to verify this information; our expectation was that decisions are mainly emotionally driven. Additionally, the hypothesis $\mathrm{H} 1$ has not been confirmed, though we expected that, because of substantial cultural differences between respondents, the motives for the selection of the destination would be different. Despite the substantial diversity between respondents, the two motives comfort and attractiveness - are similar in all groups. We expect that more conclusions can be drawn from further studies when differences in such characteristics are taken into account:

- age - below 25; 25-35; above 36, for example,

- objectives/goals/expectations of results associated with the journey: relaxation, active recreation, sightseeing, participation in cultural events, visiting family and/or friends, education, getting some income/working travel, and

- family status single - formal/informal relationships, with/without kids, etc.

Should such data be available, more precise responses to certain questions could be provided: What? For what respondents? What is most important for them? And keeping in mind that such responses aid in the planning of marketing/advertising communications.

Characteristically, items relative to "comfort" and "attractiveness" are closely linked to those elements that are important to the selection of the destination as presented in Table 1. In the opinion of authors, it makes a lot of sense: young people (students) want to spend holidays comfortably, to be in a reasonably good hotel, to spend time having access to attractive places, to get a good meal, to do some shopping - all within acceptable price/cost limits. Yet we believe that further detailed study in these areas are needed in order to benefit tourists and travel agencies. Perhaps a modified approach could be used with different types of traveler: natural, urban, clubbers, groups, single explorers, etc., with very complex individual motives. First question: why? Then, where? Then, how? There will be as many reasons as there are travelers.

\section{Acknowledgments}

We thank our colleagues for distributing questionnaires to students. In particular: H. Lin, P. Bruning, and B. Sharma from the University of New Brunswick, Fredericton, Canada; E. Gołębiowska and E. Klamut from the University of Social Sciences, Warsaw, Poland; J. C. Lartigue, A. McKenzie, A. Williams, and A. Donaldson-Jeffrey from Roytec - University of West Indies, Port of Spain, T\&T. Special appreciation is forwarded to Tadeusz Nasierowski for verification of statistical concepts.

\section{$7 \quad$ References}

[1] Bizirgianni, I., Dionysopoulou, P., 2013. The Influence of Tourist Trends of Youth Tourism Through Social Media (SM) \& Information and Communication Technologies, the $2^{\text {nd }}$ International Conference on Integrated information; Procedia - Social and Behavioral Sciences, 73, pp.652-660.

[2] Blumenberg, E., Taylor, B., Smart, M., Ralph, K., Wander, M. and Brumbagh, S., 2012. What's Youth Got To Do With it? Exploring the Travel Behavior of Teens and Young Adults. University of California Transportation Center, University of California, Faculty Research.

[3] Bond. N., Falk J., 2013. Tourism and IdentityRelated Motivations: Why Am I Here (And Not There)? International Journal of Tourism Research, 15, pp.430-442.

[4] Buchta, K., Skiert, M., 2012. Wzorce aktywności turystycznej studentów turystyki i rekreacji w uczelni wychowania fizycznego (Patterns of 
Tourist Activity of Students in Tourism and Recreation in the Physical Education College). Zeszyty Naukowe Uniwersytetu Szczecińskiego, No. 699, Ekonomiczne Problemy Usług, pp.23-32.

[5] Buhalis, D., 2000. Marketing the Competitive Destination of the Future. Tourism Management, 21 (1), pp.97-116.

[6] Chen, Ch-F., Tsai, D.C., 2007. How Destination Image and Evaluative Factors Affect Behavioral Intentions? Tourism Management, 28 (4), pp. 1115-1122.

[7] Chen, J.S., Gursoy, D., 2001. An Investigation of Tourists' Destination Loyalty and Preferences. International Journal of Contemporary Hospitality, 13 (2), pp.79-85.

[8] Cho. V., 2010. A Study of the Non-economic Determinants in Tourism Demand. International Journal of Tourism Research, 12, pp.307-320.

[9] Crompton, J., 1992. Structure of Vacation Destination Choice Sets. Annals of Tourism Research, 10 (3), pp.420-434.

[10] Decorp, A., Snelders, D., 2003. A Grounded Typology of Vacation Decision-Making. Tourism Management, 26 (2), pp.121-132.

[11] Demeter, T., Bratucu, G., 2014. Typologies of Youth Tourism. Bulletin of Transilvania University of Brasov, 7 (1), pp.115-166.

[12] Dionysopoulou, P., Mylokanis, J., 2013. Youth Tourists' Profile and Their Travel Choices as Influence by Social Media Networks. European Journal of Hospitality and Tourism Research, 1 (3), pp.22-35.

[13] Doran, R., Larsen. S. and Wolff. K., 2015. Different but Similar: Social Comparison of Travel Motives Among Tourists. International Journal of Tourism Research, 17, pp.555-563.

[14] Dwyer, L., Kim, Ch., 2010. Destination Competitiveness: Determinants and Indicators. Current Issues in Tourism, 6 (5), pp.369-414.

[15] Eugenio-Martin. J.L., 2003. Modeling Determinants of Tourism Demand as a Five-Stage Process: A Discrete Choice Methodological Approach. Tourism and Hospitality Research, 4 (4), pp.341-354.

[16] Fyhri, A., Hjorthol, R., Mackett, R.L, Fotel, T.N. and Kytta, M., 2011. Children's Active Travel and Independent Mobility in Four Countries: Development, Social Contributing Trends and Measures. Transport Policy: 18 (5), pp.703-710.
[17] Graja-Zwolińska, S., Spychała, A., 2012. Aktywność turystyczna wielkopolskich seniorów (Tourist Activity of Wielkopolska Seniors). Prace Naukowe Uniwersytetu Ekonomicznego we Wroclawiu No. 259, pp.54-63.

[18] Grzinic, J., Saftic, D., 2012. Approach to the Development of Destination Management in Croatian Tourism. Journal of Contemporary Management, 17 (1), p.59-74.

[19] Hankinson, G., 2009. Managing Destination Brands: Establishing a Theoretical Foundation. Journal of Marketing Management, 25 (1-2), pp.97-115.

[20] Kaushik, N., Kaushik, J., Sharma, P. and Rani, S., 2010. Factors Influencing Choice of Tourist Destinations: A Study of North India. Journal of Brand Management, 7 (1-2), pp.116-132.

[21] Kim, K, Noh, I. and Jogaratham, G., 2007. College Student Travel: A Revised Model of Push Motives. Journal of Vacation Marketing, 13 (1), pp.73-85

[22] Kim, K-Y., Jogaratham, G., 2002. Travel Motivations: A Comparative Study of Asian International and Domestic American College Students. Journal of Travel and Tourism Marketing, 13 (4), pp.61-82.

[23] King, C., Chen, N. and Funk D.C., 2015. Exploring Destination Image Decay: A Study of Sport Tourists' Destination Image Change After Event Participation. Journal of Hospitality and Tourism Research, 39 (1), pp.3-31.

[24] Kozak, M., Rimmington, M., 1999. Measuring Tourist decompetitiveness: Conceptual Considerations and Empirical Findings. International Journal of Hospitality Management, 18 (3), pp.273-283.

[25] Lam, T., Hsu, C.H.C., 2005. Predicting Behavioral Intention of Choosing a Travel Destination. Tourism Management, 27 (4), pp.589-599.

[26] Mechinda, P., Serirat, S., Papaijit, N., Lertwannawit, A. and Anuwichanont, J., 2010. The Relative Impact of Competitiveness Factors and Destination Equity on Tourist's Loyalty: in Koh Chang, Thailand. International Business \& Economics Research Journal, 9 (10), pp.99-114.

[27] Moisa, C.O., 2010. The Distinctiveness of the Youth Travel Product. Annales Universitatias Apulensis Series Oeconomica, 12 (2), pp.638648. 
[28] Nasierowski, W., Dębski, M., 2015. Zarządzanie przekazem marketingowym w turystyce adresowanym do ludzi młodych: wybrane zagadnienia (Managing Marketing Communication in Tourism Addressed to Young People: Selected Issues). Przedsiębiorczość i Zarzadzanie, XVI (12), part 3, pp.111-126.

[29] Navickas, V., Malakauskaite, A., 2009. The Possibilities for the Identification and Evaluation of Tourism Sector Competitiveness Factors. Engineering Economics, 1 (61), pp.37-44.

[30] Niezgoda, A., 2012. Popyt turystyczny - uwarunkowania i perspektywy rozwoju (Tourist Demand - Conditions and prospects for Development). Zeszyty Naukowe Uniwersytetu Szczecińskiego nr 697, Ekonomiczne Problemy Usług, 82, pp.11-25.

[31] Panasiuk, A., 2014. Rynek turystyczny. Studium przypadku (Tourist Market. Case Study). Warszawa: Difin.

[32] Panasiuk, A., 2015. Problemy asymetrii informacji na rynku turystycznym w obszarze transakcyjnym (Problems of Information Asymmetry in the Tourist Market in the Transactional Area). Prace naukowe Uniwersytetu Ekonomicznego we Wrockawiu, 379, pp.430-438.

[33] Panter, J.R., Jones, A.P. and van Sluijs, E.MF., 2008. Environmental Determinants of Active Travel in Youth: A Review and Framework for Future Research. International Journal of Behavioral Nutrition and Physical Activity, 5 Special section, pp.1-14.

[34] Park. S.Y., Jei S.Y., 2010. Determinants of Volatility on International Tourism Demand for South Korea: an Empirical Note. Applied Economics Letters, 17, pp.217-223.

[35] Ryan, C., Zhnag, Z., 2006. Chinese Students: Holiday behaviors in New Zealand. Journal of Vacation Marketing, 13 (2), pp.91-105.

[36] Sirakaya, E., McLellan, R. and Uysal, M., 1996. Modeling Vacation Destination Decisions: A Behavioral Approach. Journal of Travel and Tourism Marketing, 5(1-2), pp.57-75.
[37] Śniadek, J., 2006. Age of Seniors - a Challenge for Tourism and Leisure Industry. Studies in Physical Culture and tourism, 13, supplement.

[38] Sung, S. and Hsu, C.H.C., 2010. International Student's Travel Characteristics: An Exploratory Study. Journal of Travel and Tourism Marketing, 5 (3), pp.277-283.

[39] The Power of Youth Travel (2011). AM Reports, UNWTO, 2, pp.6-8.

[40] Tibon, M.V.P., 2012. A Push Motivation Model of Filipino Youth Travel. Journal of Modern Accounting and Auditing, 8 (9), pp.1392-1397.

[41] UNWTO, 2015. Tourism Highlights.

[42] Vanhove, N., 2002. Tourism Policy: Between Competitiveness and Sustainability - The Case of Bruges. The Tourist Review, 57 (3), pp.34-40.

[43] Vukic, M., Kuzmanovic M. and Stankovic M., 2015. Understanding the Heterogeneity of Generation Y's Preferences for Travelling: a Conjoint Analysis Approach. International Journal of Tourism Research, 17 (5), pp.482-491.

[44] WCY, 2016. World Competitiveness Report, Lausanne.

[45] Websters Third International Dictionary, 1986. Merriam-Webster Inc.

[46] Wong, Ch-K.S., Kwong, W-Y.Y., 2003. Outbound Tourists' Selection Criteria for Choosing all-Inclusive Package Tours. Tourism Management, 25 (5), pp.581-592.

[47] Yoon, K., 2014. Transnational Youth Mobility in the Neoliberal Economy of Experience. Journal of Youth Studies, 17 (8), pp.1014-1028;

[48] Yousefi. M., Marzuki. A., 2012. Travel Motivations and the Influential Factors: the Case of Penang, Malaysia. Anatolia - An International Journal of Tourism and Hospitality Research, 23 (2), pp.169-176.

[49] Youth Travel Matters. Understanding the Global Phenomenon of Youth Travel, 2008. Word Tourism Organization, Madrid. 